\title{
Does sexual behaviour of people with HIV reflect antiretroviral therapy as a preventive strategy? A cross-sectional study among outpatients in Kenya
}

\author{
Kennedy Nkhoma ${ }^{1 *}$ D, Aabid Ahmed ${ }^{2}$, Zipporah Alli ${ }^{3}$, Lorraine Sherr ${ }^{4}$ and Richard Harding ${ }^{1}$
}

\begin{abstract}
Background: The World Health Organisation (WHO) advocates early initiation of HIV treatment as a prevention strategy among people living with HIV. There is strong evidence for the effectiveness of antiretroviral therapy (ART) as a preventive tool for HIV transmission. We aimed to determine the sexual behaviour of HIV outpatients and assess if it reflects the current preventive strategy for HIV transmission.

Methods: We conducted a cross-sectional study among adult (aged at least 18 years) patients with confirmed HIV diagnosis, and aware of their diagnosis, attending HIV outpatient care in Kenya. Data were gathered through selfreport (using validated questionnaires) and file extraction. Multivariate logistic regression assessed the association between sexual risk taking behaviour controlling for gender, HIV clinical stage, HIV treatment status, Tuberculosis (TB) treatment status, and CD4 count.

Results: We recruited $n=400$ participants ( $n=280[70 \%]$ female gender). The mean age was $39.4(S D=9.9)$ years. The mean CD4 count was $393.7(S D=238.2)$ and ranged from 2 to 1470 cells $/ \mathrm{mm}^{3} . N=61(15.64 \%)$ were on TB treatment. The majority $(n=366,91.5 \%)$ were on ART. Just over half $(n=202,50.5 \%)$ reported having a sexual partner. Of these $n=33(16.1 \%)$ reported having unprotected sexual intercourse with a person of unknown HIV status in the previous 3 months.

Multivariate analysis showed that participants not on ART (HIV treatment) were more likely to report unprotected sexual intercourse compared to those who were on ART (odds ratio .25, 95\% Cl .09 to .69; $P=0.007$ ).

Participants at early stage of HIV infection (stages $1 / 2$ ) were more likely to report unprotected sexual intercourse compared to participants at advanced HIV infection (stages 3/4) (odds ratio $.34,95 \% \mathrm{Cl} .13$ to .92; $P=0.035$ ). Males participants were more likely to be involved in sexual risk taking behaviours compared to female participants (odds ratio $.36,95 \% \mathrm{Cl} .16$ to $.82 ; P=0.015)$. TB treatment status, and CD4 count were not significantly associated with sexual risk taking.
\end{abstract}

Conclusion: Participants not on ART have more unprotected sexual intercourse than those who are on ART. This calls for the need to scale up coverage and early ART initiation in order to reduce transmission of HIV.

Keywords: Sexual risk taking, HIV/AIDS, Antiretroviral therapy

\footnotetext{
* Correspondence: kennedy.nkhoma@kcl.ac.uk

${ }^{1}$ Faculty of Nursing, Midwifery and Palliative Care, Cicely Saunders Institute of

Palliative Care Policy and Rehabilitation, Denmark Hill Campus, King's College London, Bessemer Road, London SE5 9PJ, UK

Full list of author information is available at the end of the article
}

(c) The Author(s). 2019 Open Access This article is distributed under the terms of the Creative Commons Attribution 4.0 International License (http://creativecommons.org/licenses/by/4.0/), which permits unrestricted use, distribution, and reproduction in any medium, provided you give appropriate credit to the original author(s) and the source, provide a link to the Creative Commons license, and indicate if changes were made. The Creative Commons Public Domain Dedication waiver (http://creativecommons.org/publicdomain/zero/1.0/) applies to the data made available in this article, unless otherwise stated. 


\section{Background}

Kenya has one of the highest prevalence and burden of HIV infection. In terms of HIV epidemic, Kenya seats on fourth position alongside Mozambique and Uganda. At the end of 2017, there were 1.5 million people living with HIV in Kenya with 4.8\% adult prevalence [1,2].

This continued high prevalence of HIV in Kenya among adults are likely to be driven by a range of sexual behaviours such as inconsistent condom use and multiple sexual partners [1]. There have been inconsistent reports about sexual behaviour of people living with HIV (PLWH). Some studies report that those on antiretroviral therapy (ART) are more likely to engage in unprotected sexual intercourse, for instance studies involving the youth [3, 4] women [5], gay men $[6,7]$ and adults $[8,9]$, while other studies report that those on ART are less likely to engage in unprotected sex [10-13]. An estimated 30\% of new HIV transmissions are among people from key populations such as gay men and people who inject drugs [14]. Among people who inject drugs $18.3 \%$ are HIV positive [14]. Early initiation of ART has been reported to reduce HIV transmission among discordant couples. A trial among predominantly heterosexual discordant couples reported $96 \%$ reduction of risk of HIV transmission [15]. A recent prospective observational study among discordant couples reported zero within couple transmission of HIV after 13 months follow-up [16]. Systematic reviews of randomised controlled trials (RCT) and observational studies also report that ART reduces HIV transmission among discordant couples due to undetectable viral loads $[17,18]$.

There has been some significant progress in terms of implementing the 90-90-90 UNAIDS policy in Kenya which aims to ensure that $90 \%$ for of those with HIV know their status, that $90 \%$ of those with HIV are on treatment and $90 \%$ of those on treatment will be virally suppressed. At the end of 2018, $75 \%$ of the population who are HIV positive started ART (HIV treatment). Furthermore there has been a decline in mortality from 51 , 000 in 2010 to 36,000 in 2015 due to increased uptake of ART [19, 20].

Potent HIV prevention strategies are required to ensure there is no HIV transmission from infected persons to uninfected partners.

We therefore conducted a cross-sectional study among HIV patients to determine if their sexual behaviour reflects a new understanding of ART as a prevention strategy for reducing the spread of HIV.

\section{Methods}

Informed by the health belief model, which attempts to explain and predict health behaviours among individuals [21], we carried out a cross-sectional study using self-report and supplemented this with clinic data drawn from file extraction. We recruited adults, at least 18 years old,
HIV positive and aware of their status. Participants were attending HIV outpatient care at Bomu hospital in Mombasa, Kenya. We excluded patients younger than 18 years of age, and those not aware of their diagnosis, or those unable to give self-report data with assistance from the researcher due to significant physical or psychological impairment. Kenyan Medical Research Institute provided ethics approval for this study.

\section{Procedures}

The details of the study procedures have been explained in our previous publications [22, 23]. We employed a research assistant who implemented all research activities at the study site.

\section{Data collection}

The following variables were extracted from patient's records by the researcher: $\mathrm{CD}_{4}$, HIV treatment status and $\mathrm{TB}$ treatment status. We planned to extract data on viral load, but these data were not available for the majority of the participants. The other data were self-report and the researcher used a private room at the HIV clinic to collect this data. The researcher recorded responses as participants gave answers verbally. This procedure ensured that all the questionnaires were completed by the researcher, thereby reducing any potential response bias which may occur by mixing self-completion and researcher-completion data. We used the following tools to gather data, which have previously been used in subSaharan Africa among people with HIV:

1. Sexual behaviour, and adherence questionnaire: Sexual behaviour section consists of two items: (1) sexual partners in the last 3 months, and (2) unprotected sexual intercourse with a person of unknown HIV status in the previous 3 months. The adherence questionnaire asks participants to record the number of doses they have missed in the past 7 days $[24,25]$. This questionnaire was recently used in a clinical trial conducted in Kenya among HIV patients [26, 27]. Questions on HIV risk behaviour were asked face-to-face by a researcher who read the questions aloud to the participants and thereafter recorded self-reported responses.

2. Demographics, and socioeconomic status: Demographics and socioeconomics data were gatherer using the Demographic and Health Survey (DHS) questionnaire [28]. This consists of variables such as house construction, possession of items, fuel supply, and water source. These variables were used to calculate the wealth of the participants. The wealth quintile variable was created in line with the methods of DHS [28]. We used factor analysis with principal component analysis to create a continuous 
variable which was then converted into quintiles. DHS has previously been used in HIV research in sub-Saharan Africa [27, 29].

\section{Sample size calculation}

We calculated our sample size based on HIV prevalence in Kenya. We have provided these details in our previous publications [22, 23].

\section{Data analysis}

We used Stata version 14 to analyse the data [30]. Descriptive statistics were used to profile the demographic, socioeconomic and clinical characteristics of participants. WHO clinical stages were combined ( 1 and 2 combined to one group, likewise 3 and 4, because of small numbers).

A series of logistic regression analysis were conducted. The dependent outcome was sexual risk taking, i.e. penetrative sexual intercourse without a condom in the previous 3 months with a person that the participant was not sure also had HIV (binary variable: yes/no). Covariates were demographic variables (age, gender, education, and wealth in quintiles), clinical variables (WHO clinical stage: $1 / 2$ vs $3 / 4$, CD 4 count in quintiles, TB treatment: yes/no, ART treatment: yes/no). Initially we conducted a univariate analysis for demographic, clinical variables and outcome variable. We then conducted adjusted/multivariate analysis for demographic variables and outcome variable falling within less than $25 \% p$ value [31]. Clinical variables (HIV treatment status, CD4 count, WHO clinical stage, TB treatment status) were forced into the multivariate model regardless on the outcome of the univariate.

This is because these are confounding variables frequently associated with HIV risk behaviours. We were interested in risk factor modelling not just prediction. Studies have shown that researchers can return confounding variables as long as sample sizes are larger because correct retention increases with sample size [32].

Sexual behaviour is frequently associated with clinical variables such as treatment status [7]. All cases with missing data were excluded from the models.

\section{Results}

Demographic characteristics of the participants are presented in Table 1 . We approached $n=475$, of these $n=$ 400 consented and were recruited, with a response rate of $84.2 \%$. The mean age of the participants was 39.4 (SD 9.9) years. Most of the participants $(n=280,70 \%)$ were females. Just over half of our participants $(n=213$, $53.25 \%$ ) attended primary school, and just over a quarter of the our participants ( $n=113,28.25 \%$ ) went to secondary school.

\section{Treatment variable and sexual behaviour variables}

The majority of the patients were taking ART $(n=366$, 91.5\%), with $n=61$ (15.64\%) on concurrent TB treatment. The majority were on Nucleoside/nucleotide reverse transcriptase inhibitors (NRTIs/NtRTIs) $(n=262,90.50 \%)$ and Non-nucleoside reverse transcriptase inhibitors (NNRTIs) ( $n=319,79.75 \%)$ as presented on Table 2 . The mean CD4 count was $393.7(\mathrm{SD}=238.2)$ and ranged from 2 to 1470 cells $/ \mathrm{mm}^{3}$. The majority of our participants had advanced HIV/AIDS infection (stage III/IV) $(n=348,87 \%)$. Most of these participants had disclosed their HIV status at least to one person ( $n=373,93.25 \%)$. Adherence in the preceding 7 days was $75.5 \%$ fully adherent $(n=302)$, with $16 \%$ reported missing 1 or more doses $(n=64)$. The mean (SD) number of doses missed was $0.36(\mathrm{SD}=1.28)$ and ranged from 1 to 14 doses. Of the $n=400$ participants, just over half $n=202$ (50.5\%) reported having one or more sexual partners in the last 3 months. Of those who reported having a sexual partner in the previous 3 months $n=33$ (16.1\%) reported that they had unprotected sex with a person of unknown HIV status.

\section{Univariate analysis}

Table 3 shows univariate analysis of the logistic regression model. Sexual risk taking was significantly associated with being on HIV treatment and gender.

Participants who were not on ART (HIV treatment) were likely to report sexual risk-taking behaviour (unprotected sexual intercourse) compared to participants who were on ART (odds ratio .28, 95\% CI .11 to .74; $P=0.010)$. Male participants were more likely to be involved in sexual risk-taking behaviours compared to female participants (odds ratio .42, 95\% CI .19 to .89; $P=$ 0.024). Age, clinical stage, CD4 count, education, wealth were not significantly associated with sexual risk taking.

\section{Multivariate analysis}

When adjustments were made (Table 4) for gender, clinical variables (HIV treatment (yes/no), CD4count (quintiles), TB treatment (yes/no), and HIV clinical stage) in the multivariate analysis, ART (HIV treatment), gender and clinical stage were significantly associated with sexual risk taking.

Participants who were not on ART were more likely to report unprotected sexual intercourse with someone of unknown HIV status in the previous 3 months compared to participants who were on ART (odds ratio .25, 95\% CI .09 to .69; $P=0.007$ ).

Participants who were at stages $1 / 2$ were more likely to have unprotected sexual intercourse than participants who were at stages $3 / 4$ of $\mathrm{HIV}$ infection (odds ratio .34, 95\% CI .13 to .92; $P=0.035$ ).

Male participants were more likely to be involved in sexual risk taking behaviour compared to female participants (odds ratio .36, $95 \% \mathrm{CI} .16$ to .82 ; $P=0.015$ ). 
Table 1 Demographic and clinical characteristics $(N=400)$

Demographic characteristics

Gender
Male
Female
Mean age (SD)
Relationship
In a relationship
Not in relationship
Education
One or two years
Primary or $>2$ years
Secondary
Diploma
Degree or higher
Wealth quintile
Poorest
Middle poor
Middle
Middle wealthy
Wealthiest
Behavioural characteristics
Told someone HIV Status
Yes
No
Misssed dose and unprotected
sexual intercourse
Yes missed doses
Noses
Mes

sexual intercourse

Missed 1 or more doses but did not have unprotected sex

Missed 1 or more doses and had unprotected sex

Missed 1 or more doses and number of sexual partners

No sexual partner

One sexual partner

Sexual partner

No

One sexual partner

More than one sexual partner

Unprotected sexual intercourse with someone of unknown HIV status ${ }^{c}$

Yes
Table 1 Demographic and clinical characteristics $(N=400)$ (Continued)

\begin{tabular}{|c|c|}
\hline No & $169(82.44 \%)$ \\
\hline \multicolumn{2}{|l|}{ Sexual behaviour } \\
\hline With men only & $264(66 \%)$ \\
\hline With women only & $133(33.25)$ \\
\hline With men and women & $3(0.75 \%)$ \\
\hline \multicolumn{2}{|l|}{ Sexual orientation by gender } \\
\hline \multicolumn{2}{|l|}{ Males } \\
\hline Sex with men only & $18(15 \%)$ \\
\hline Sex with women only & $101(84.17 \%)$ \\
\hline $\begin{array}{l}\text { Sex with men } \\
\text { and women }\end{array}$ & $1(0.83 \%)$ \\
\hline \multicolumn{2}{|l|}{ Females } \\
\hline Sex with men only & $246(87.86 \%)$ \\
\hline Sex with women only & $32(11.43 \%)$ \\
\hline $\begin{array}{l}\text { Sex with men } \\
\text { and women }\end{array}$ & $2(0.71 \%)$ \\
\hline \multicolumn{2}{|l|}{ Unprotected by gender } \\
\hline Males & $17(51.52)$ \\
\hline Females & $16(48.48)$ \\
\hline $\begin{array}{l}\text { Unprotected sex } \\
\text { with men only }\end{array}$ & $19(57.58)$ \\
\hline \multicolumn{2}{|l|}{$\mathrm{CD}_{4}$ count } \\
\hline Mean & $393.7(238.2)$ \\
\hline Range & $2-1470$ \\
\hline \multicolumn{2}{|l|}{ WHO Stage } \\
\hline Stage $1 / 2$ & $52(13 \%)$ \\
\hline Stage $3 / 4$ & $348(87 \%)$ \\
\hline \multicolumn{2}{|l|}{ Patient on ART } \\
\hline Yes & $366(91.5 \%)$ \\
\hline No & $34(8.5 \%)$ \\
\hline \multicolumn{2}{|l|}{$\begin{array}{l}\text { Unprotected sex } \\
\text { and ART status }\end{array}$} \\
\hline On ART & $25(75.76)$ \\
\hline Not on ART & $8(24.24)$ \\
\hline \multicolumn{2}{|l|}{ Patient on TB treatment ${ }^{\mathrm{d}}$} \\
\hline Yes & $61(15.64 \%)$ \\
\hline No & $329(84.36 \%)$ \\
\hline
\end{tabular}

${ }^{\mathrm{a}} 1$ missing

${ }^{b} 34$ not on ART

$32(50.00 \%)$

' 198 did not have a sexual partner

d 10 missing

198 (49.50\%)

187 (46.75\%)

$15(3.75 \%)$

Discussion

Results from this study showed that participants who were not on ART were likely to have unprotected sexual intercourse with someone of unknown HIV status in the previous 3 months compared to participants who were on ART. Our results show 
Table 2 ART Regimen

\begin{tabular}{lc}
\hline ART classification & Frequency \\
\hline $\begin{array}{l}\text { Nucleoside/nucleotide reverse } \\
\text { transcriptase inhibitors (NRTIs/NtRTIs) }\end{array}$ & $362(90.50)$ \\
$\begin{array}{l}\text { Non-nucleoside reverse } \\
\text { transcriptase inhibitors (NNRTIs) }\end{array}$ & $319(79.75)$ \\
Protease inhibitors & $16(4.00)$ \\
Integrase inhibitors & $1(0.25)$ \\
\hline
\end{tabular}

high risk of HIV transmission among participants not on ART.

This result is an important public health concern because participants were at risk of acquiring other viruses (re-infection with new strains of HIV from people they were having unprotected sexual intercourse with, (assuming they were also HIV positive and not on treatment), furthermore they were at risk of spreading other forms of viruses (onward transmission of HIV) [33, 34]. However this was going to be a different story if these respondents were on ART (HIV treatment) because the risk of transmission is reduced when one is on HIV treatment and viral load has been suppressed [1]. International Business Times (2013) reported that in 2013, condom distribution fell far below demand in Kenya for 2 years because they were not budgeted for [35]. This may well have contributed to reasons why participants practised unprotected sexual intercourse. Moreover there were reports that men were reusing condoms, or were using plastic bags due to shortage of free condom supply in public facilities [36]. On the other hand, condoms may be available but this does not guarantee that they will be used. A demographic health survey reported that only $40 \%$ of women and $43 \%$ of men with multiple sexual partners used a condom in Kenya [37].

Our results are consistent with recent evidence from a study conducted in South Africa which reported that
$25 \%$ of the sample awaiting to start ART had unprotected sexual intercourse with HIV negative or untested partners [38, 39]. However previous work from a crosssectional study conducted in South Africa [40] and meta-analysis of cross-sectional studies conducted in sub-Saharan Africa [41] reported that ART is significantly associated with decreased sexual risk behaviours.

Another important finding from this study is that participants who were at stages $1 / 2$ were more likely to have unprotected sexual intercourse than participants who were at stages $3 / 4$ of HIV infection. This is possibly related to the fact that patients at stage 3/4 of HIV infection are eligible for ART and received health education and information about positive living with HIV which includes practising safe sex, such as using condoms. Our results are in line with a prospective, longitudinal study conducted in Uganda which reported that unprotected sexual intercourse decreased after ART initiation [42]. Another explanation for higher sexual risk taking at stages $1 / 2$ of HIV infection may be due to the fact that at stage $3 / 4$ participants were quite sick and therefore they did not have interest in sexual intercourse. A cross-sectional internet based survey in the USA reported sexual problems among gay men with advanced HIV/AIDS infection [43].

Male participants were more likely to be involved in sexual risk taking behaviour compared to female participants. Men dominate sexual relationships hence practice unsafe sex even when they know the risks associated with this behaviour [19].

\section{Study strengths}

We used questionnaires validated in local population and these have previously been used among people with HIV in a randomised control trial [26, 27]. An experienced researcher administered the questionnaires face-to-face with study participants. All questions were read aloud to the participants and thereafter responses were recorded. This

Table 3 Associations of factors with sexual risk taking (unprotected sexual intercourse with someone of unknown status): Univariate analysis $(n=202)$

\begin{tabular}{|c|c|c|c|c|}
\hline Outcome/dependent variable & Independent variable & Odds ratio $(95 \% \mathrm{Cl})$ & Z score & $P$ value \\
\hline \multirow{8}{*}{$\begin{array}{l}\text { Sexual risk taking (Unprotected } \\
\text { sex with someone of unknown } \\
\text { status: yes or no) }\end{array}$} & Age & 0.98 (0.95 to 1.03$)$ & -0.54 & 0.59 \\
\hline & Women vs men (ref female) & 0.42 (0.19 to 0.89$)$ & -2.26 & $0.024^{*}$ \\
\hline & WHO stage $1 / 2$ vs $3 / 4$ & $0.42(0.17$ to 1.06$)$ & -1.85 & $0.065^{*}$ \\
\hline & ART (HIV treatment) (ref yes) & 0.28 (0.11 to .74) & -2.57 & $0.010^{*}$ \\
\hline & TB treatment (ref yes) & 1.14 (0.43 to 3.03$)$ & 0.27 & $0.79^{\S}$ \\
\hline & CD4 count (in quintile) & 1.10 (0.84 to 1.44$)$ & 0.68 & $0.49^{\S}$ \\
\hline & Education & 1.07 (0.65 to 1.75$)$ & 0.27 & 0.79 \\
\hline & Wealth (quintile) & 1.01 (0.78 to 1.32$)$ & 0.09 & 0.93 \\
\hline
\end{tabular}

* $<25 \%$ significance and included in multivariate analysis

${ }^{5}$ Not significant at $25 \%$ but forced into the multivariate analysis 
Table 4 Associations of factors with sexual risk taking (unprotected sexual intercourse with someone of unknown HIV status): Multivariate analysis $(n=202)$

\begin{tabular}{|c|c|c|c|c|}
\hline Outcome/dependent variable & Independent variable & Odds ratio $(95 \% \mathrm{Cl})$ & Z score & $P$ value \\
\hline \multirow{5}{*}{$\begin{array}{l}\text { Sexual risk taking (Unprotected } \\
\text { sex with someone of unknown } \\
\text { status: yes or no) }\end{array}$} & ART (HIV treatment) (ref yes) & 0.25 (0.09 to .69) & -2.68 & $0.007^{*}$ \\
\hline & WHO stage $1 / 2$ vs $3 / 4$ & 0.34 (0.13 to 0.92$)$ & -2.11 & $0.035^{*}$ \\
\hline & Men vs women (ref male) & 0.36 (0.16 to 0.82$)$ & -2.43 & $0.015^{*}$ \\
\hline & CD4 (quintiles) (ref very low) & 1.18 (0.88 to 1.59$)$ & 1.13 & 0.26 \\
\hline & TB treatment (ref yes) & 1.26 (0.45 to 3.52$)$ & 0.44 & 0.66 \\
\hline
\end{tabular}

*statistically significant

helped to reduce cases with missing data. Furthermore, we included broad relevant clinical data on patient reported outcomes. Our study had a response rate of $84.2 \%$.

\section{Limitations}

This data did not have viral load measures, one of the important variable which we could have used to understand if the unprotected sex was associated with risk of HIV transmission. We did not ask participants about sexual assault, forced sexual intercourse, alcohol and drug use and other risk factors that may predispose the transmission of HIV. These factors are important in assessing the risk of HIV transmission and infection. These data were cross-sectional therefore we cannot determine causation, but associations. We do not know if participants who had unprotected sexual intercourse were having sexual encounter with HIV negative partners which means they were at risk of transmitting HIV. A follow-up study to trace sexual partners of study participants could have helped to screen them for HIV and then offer appropriate care depending on the outcome of HIV test.

\section{Conclusions}

Kenya has to effectively implement the 90-90-90 UNAIDS policy in order to mitigate the impact of HIV in the country. It is interesting to note that in 2015, Kenya adopted the WHO recommendations to immediately offer treatment to people diagnosed with HIV. It is also interesting that in 2017 Kenya rolled-out PrEP for key populations such as injecting drug users, sero-discordant couples, commercial sex workers, and those with history of recent sexually transmitted infection. Recent UNAIDS (2018) global report shows that $75 \%$ of those living with HIV are on ART, and $63 \%$ of all people living with HIV are virally suppressed [2]. Kenya has a long way to achieve the $90-90-90$ policy by 2020. The country has to improve on scaling up ART so that all people who test positive should be put on ART.

Viral load testing needs to be conducted routinely in order to assess the effectiveness of ART and effectively monitor the 90-90-90 policy. Health education and information provision to the community on condom use to prevent the transmission of HIV infection among those not on ART treatment needs to continue and be strengthened.

\section{Abbreviations \\ AIDS: Acquired immune deficiency syndrome; ART: Antiretroviral therapy; DHS: Demographic and Health Survey; HIV: Human immune deficiency virus; RCT: Randomised Controlled Trial; TB: Tuberculosis; UNAIDS: Joint United Nations Programme on HIV/AIDS; WHO: World Health Organisation}

\section{Acknowledgements}

We would like to thank Nancy Gikaara who collected data and managed our data. We also thank participants for their enthusiasm in taking part of this study.

\section{Authors' contributions}

$\mathrm{KN}$ analysed the data under the supervision of $\mathrm{RH}$. All authors interpreted the data. KN drafted the manuscript. All authors reviewed the manuscript and each made a significant contribution to successive drafts. All authors approved the manuscript.

\section{Funding}

This study did not receive any funding.

\section{Availability of data and materials}

The datasets used and/or analysed during the current study are available from the corresponding author on reasonable request.

\section{Ethics approval and consent to participate}

All participants were provided with informed consent and signed consent form after agreeing to take part in the study. The study was approved by Kenya Medical Research Medical Institute (KEMRI/RES/7/3/1).

\section{Consent for publication}

Not applicable

\section{Competing interests}

The authors declare that they have no competing interests.

\section{Author details}

${ }^{1}$ Faculty of Nursing, Midwifery and Palliative Care, Cicely Saunders Institute of Palliative Care Policy and Rehabilitation, Denmark Hill Campus, King's College London, Bessemer Road, London SE5 9PJ, UK. ²Bomu Hospital, Mombasa, Kenya. ${ }^{3}$ Kenya Hospices and Palliative Care Association, Nairobi, Kenya.

${ }^{4}$ University College London, London, UK.

Received: 31 July 2018 Accepted: 30 August 2019

Published online: 11 September 2019

\section{References}

1. WHO/UNAIDS. Global AIDS Response Progress Reporting 2015. 2015; Available from: http://www.unaids.org/sites/default/files/media_asset/JC2 702_GARPR2015guidelines_en.pdf. 30 Aug 2016

2. UNAIDS. Global Information and Education on HIV and AIDS HIV and AIDS in KENYA 2018; Available from: https://www.avert.org/professionals/hivaround-world/sub-saharan-africa/kenya. Cited 11 Mar 2019 
3. Lightfoot $\mathrm{M}$, et al. Risk behaviors of youth living with HIV: pre-and postHAART. Am J Health Behav. 2005;29:162-72.

4. Rice E, Batterham P, Borus MJR. Unprotected sex among youth living with HIV before and after the advent of highly active antiretroviral therapy. Perspect Sex Reprod Health. 2006;38:162-7.

5. Wilson TE, et al. Changes in sexual behavior among HIV-infected women after initiation of HAART. Am J Public Health. 2004;94:1141-6.

6. Mei $\mathrm{S}$, et al. Increasing risk behaviour can outweigh the benefits of antiretroviral drug treatment on the HIV incidence among men-having-sexwith-men in Amsterdam. BMC Infect Dis. 2011;11.

7. Harding R, et al. Symptoms are highly prevalent among HIV outpatients and associated with poor adherence and unprotected sexual intercourse. Sex Transm Infect. 2010. https://doi.org/10.1136/sti.2009.038505.

8. Olley B. Higher-risk sexual behaviour among HIV patients receiving antiretroviral treatment in Ibadan, Nigeria. Afr J AIDS Res. 2008;7:71-8.

9. Diabate $S$, Alary M, Koffi CK. Short-term increase in unsafe sexual behaviour after initiation of HAART in Co^ te d'Ivoire. AIDS. 2008;22:154-6.

10. Diamond $\mathrm{C}$, et al. Use of and adherence to antiretroviral therapy is associated with decreased sexual risk behavior in HIV clinic patients. J Acquir Immune Defic Syndr. 2005;39:211-8.

11. Marcellin F, et al. Higher risk of unsafe sex and impaired quality of life among patients not receiving antiretroviral therapy in Cameroon: results from EVAL survey (ANRS 12-116). AIDS. 2010;24:S17-25.

12. Bunnel $R$, et al. Changes in sexual behaviour and risk of HIV transmission after antiretroviral therapy and prevention interventions in Uganda. AIDS. 2006;20:85-92.

13. Marshall $B D L$, et al. No evidence of increased sexual risk behaviour after initiating antiretroviral therapy among people who inject drugs. AIDS. 2010;24:2271-8.

14. Kenya National AIDS Control Council. Kenya AIDS Strategic Framework 2014/2015. 2014; Available from: http./www.undp.org/content/dam/kenya/docs/Democratic\%2 OGovernance/KENYA\%20AIDS\%20STRATEGIC\%2OFRAMEWORKpdf. 20 July 2017

15. Cohen MSMD, et al. Prevention of HIV-1 infection with early antiretroviral therapy. N Engl J Med. 2011;365(6):493-505.

16. Rodger AJ, et al. Sexual activity without condoms and risk of HIV transmission in Serodifferent couples when the HIV-positive partner is using suppressive antiretroviral therapy. JAMA. 2016;316(2):171-81.

17. Anglemyer A, Rutherford GW, Horvath T, Baggaley RC, Egger M, Siegfried N. Antiretroviral therapy for prevention of HIV transmission in HIV-discordant couples. Cochrane Database Syst Rev. 2013;(4). Art. No.: CD009153. https:// doi.org/10.1002/14651858.CD009153.pub3.

18. Muessig KE, Cohen MS. Advances in HIV prevention for Serodiscordant couples. Curr HIV/AIDS Rep. 2014;11(4):434-46.

19. UNAIDS. Prevention Gap Report; 2016. p. 1-286.

20. UNAIDS. UNAIDS Databook 2018 Available from: https://www.avert.org/ professionals/hiv-around-world/sub-saharan-africa/kenya. Cited 8 Mar 2019

21. Glanz K, Rimer BK, Lewis FM. Health behavior and health education. Theory, research and practice. San Fransisco: Wiley; 2002.

22. Nkhoma K, et al. Does being on TB treatment predict a higher burden of problems and concerns among HIV outpatients in Kenya? A cross-sectional self-report study. AIDS Care. 2018;30(Supplement 2):28-32.

23. Nkhoma $\mathrm{K}$, et al. Is symptom prevalence and burden associated with HIV treatment status and disease stage among adult HIV outpatients in Kenya? A cross-sectional self-report study. AIDS Care. 2019:1-10.

24. Sherr $L$, et al. Self-reported non-adherence to ART and virological outcome in a multiclinic UK study. AIDS Care. 2010;22(8):939-45.

25. Sherr $L$, et al. Adherence to antiretroviral treatment in patients with HIV in the UK: a study of complexity. AIDS Care. 2008;20(4):442-8.

26. Lowther K, et al. Nurse-led palliative care for HIV-positive patients taking antiretroviral therapy in Kenya: a randomised controlled trial. Lancet HIV. 2015;2(8):e328-34.

27. Lowther $\mathrm{K}$, et al. Treatment outcomes in palliative care: the TOPCare study A mixed methods phase III randomised controlled trial to assess the effectiveness of a nurse-led palliative care intervention for HIV positive patients on antiretroviral therapy. BMC Infect Dis. 2012;12:288.

28. Gwatkin DR, et al. Socio-economic differences in health, nutrition, and population. Ghana: World Bank; 2007.

29. Harding $R$, et al. Quality of life and wellbeing among HIV outpatients in East Africa: a multicentre observational study. BMC Infect Dis. 2014;14:613.

30. StataCorp. Stata Statistical Software. College Station: StataCorp LP; 2015.

31. Altman DG. Practical statistics for medical research. London: Chapman and Hall; 1991.
32. Bursac $Z$, et al. Purposeful selection of variables in logistic regression. Source Code Biol Med. 2008:3(1):17.

33. Bakeera-Kitaka S, et al. Sexual risk reduction needs of adolescents living with HIV in a clinical care setting. AIDS Care. 2008;20(4):426-33.

34. Cluver F, Elkonin D, Young C. Experiences of sexual relationships of young black women in an atmosphere of coercion : original article. SAHARA J. 2013;10(1):8-16.

35. International Business Times, Kenya battles looming condom shortage crisis as spike in HIV feared. 2013.

36. IRIN, Condom recycling highlights gaps in HIV prevention programming. 2011.

37. Kenya National Bureau of Statistics, Kenya Demographic and Health Survey. 2015.

38. Carter, M. Many South African people whose HIV has been diagnosed have unprotected sex with a serodiscordant partner before starting ART. 2016; Available from: http://www.aidsmap.com/Many-South-African-patientswhose-HIV-has-been-diagnosed-have-unprotected-sex-with-aserodiscrodant-partner-before-starting-ART/page/3057198/.21 July 2017

39. Shuper PA, et al. One in 4 HIV-positive south Africans awaiting ART initiation report Condomless sex with a Serodiscordant partner. J Acquir Immune Defic Syndr. 2016;72(3):e77-9.

40. Venkatesh KK, et al. Sexual risk behaviors among HIV-infected south African men and women with their Partners in a Primary Care Program: implications for couples-based prevention. AIDS Behav. 2012;16(1):139-50.

41. Berhan A, Berhan Y. Is the sexual behaviour of HIV patients on antiretroviral therapy safe or risky in sub-Saharan Africa? Meta-analysis and metaregression. AIDS Res Ther. 2012;9(1):14.

42. Wandera B, et al. Sexual behaviors over a 3-year period among individuals with advanced HIV/AIDS receiving antiretroviral therapy in an urban HIV clinic in Kampala, Uganda. J Acquir Immune Defic Syndr (1999). 2011;57(1):62-8.

43. Shindel AW, et al. Sexual dysfunction, HIV, and AIDS in men who have sex with men. AIDS Patient Care STDs. 2011;25(6):341-9.

\section{Publisher's Note}

Springer Nature remains neutral with regard to jurisdictional claims in published maps and institutional affiliations.
Ready to submit your research? Choose BMC and benefit from:

- fast, convenient online submission

- thorough peer review by experienced researchers in your field

- rapid publication on acceptance

- support for research data, including large and complex data types

- gold Open Access which fosters wider collaboration and increased citations

- maximum visibility for your research: over $100 \mathrm{M}$ website views per year

At BMC, research is always in progress.

Learn more biomedcentral.com/submissions 